\title{
Intraoperative Auditory Evoked Potential Monitoring for Anaesthesia Depth and Utilization of Inhaled Isoflurane
}

\author{
Kunal Tewari ${ }^{1}$, T. V. S. P. Murthy ${ }^{2}$ \\ ${ }^{1}$ Department of Anaesthesia, INHS Asvini, Mumbai, India \\ ${ }^{2}$ Department of Anaesthesia, Army Hospital (Referral and Research), New Delhi, India \\ Email: doctorkunaltewari@gmail.com
}

How to cite this paper: Tewari, K. and Murthy, T.V.S.P. (2017) Intraoperative Auditory Evoked Potential Monitoring for Anaesthesia Depth and Utilization of Inhaled Isoflurane. Open Journal of Anesthesiology, 7, 109-119.

https://doi.org/10.4236/ojanes.2017.74011

Received: March 18, 2017

Accepted: April 27, 2017

Published: April 30, 2017

Copyright $\odot 2017$ by authors and Scientific Research Publishing Inc. This work is licensed under the Creative Commons Attribution International License (CC BY 4.0).

http://creativecommons.org/licenses/by/4.0/

\section{cC) (i) Open Access}

\begin{abstract}
Background: Hypnosis monitoring has been shown to reduce the incidence of awareness. A-line ARX-Index ${ }^{\text {mix }}$ (AAI) derived from auditory evoked potentials (AEP) represents as a numerical variable depth of anaesthesia. Objectives: To study the efficacy of AEP as an indicator of anaesthetic depth and monitor intraoperative awareness in neurosurgical patients by using the AAI scale. Design: Prospective cohort study is used. Setting: The study is in Neurosurgical centre of Tertiary care hospital. Participants: Neurosurgical patients requiring general anaesthesia with duration of surgery between $90-150$ minutes were enrolled for the study. Intervention: Patients in Group 1 (control) were monitored by conventional methods. Patients in Group 2 (study) underwent intraoperative monitoring by using the AEP monitor. Primary outcome: To study the efficacy of AEP monitoring and AAI index for monitoring the depth of anaesthesia and reducing the incidence of awareness. Results: There was no significant difference in the intraoperative haemodynamic responses measured between the two study groups $(p>0.5)$. There was no significant difference in the identification of intraoperative awareness by using conventional parameters between the two groups $(p>0.5)$. There was also a significantly faster time to recovery for patients in Group $2(p<0.05)$. Conclusion: Hypnosis monitoring using AEP monitor/AAI in neurosurgical patients under general anaesthesia did not show any significant difference in haemodynamic response and intraoperative awareness but had significant lower consumption of volatile anaesthetic with cost sparing effect and a faster recovery time as compared to conventional monitoring.
\end{abstract}

\section{Keywords}

A-Line ARX-Index, Anaesthesia Depth, Auditory Evoked Potential, Intraoperative Awareness, Post-Traumatic Stress Disorder 


\section{Introduction}

Conscious awareness with recall is a persistent complication of general anaesthesia (GA). Adequate application of technology with awareness of its limitations in order to reduce complications associated with GA is the keystone [1]. In order to achieve this, monitoring the depth of anaesthesia is of great importance [2]. Unlike the administration of adequate analgesia, the measureable end-points for adequate anaesthesia are not well described. The only reliable endpoint for consciousness is absence of response to a voice command, but this does not distinguish light from deep sleep [3]. Achieving adequate depth of anaesthesia during surgical procedures is desirable. Deep level of anaesthesia, resulting in cardiovascular depression (easy to detect) and prolonged awakening times (rather harmless), is of minor clinical interest, while light anaesthesia is difficult to detect and disturbing from the patients' point of view. Therefore, assessment of the depth of anaesthesia is fundamental to anaesthetic practice [2]. Several monitoring devices based on the principle of passively processed EEG have been developed out of which the Bi-spectral index Scale ${ }^{\text {tix }}$ (BIS) and the A-line ARX-Index (AAI) are two such scales. BIS shows good correlation with behavioural assessment of level of consciousness while studies have shown mid-latency auditory evoked potentials (MLAEP) in AAI to have high sensitivity and specificity with level of sedation during anaesthesia [4]. Volatile inhalational agents like Isofluorane reduce the amplitudes of MLAEPs and increase their latency in a dose-dependent fashion. AAI has been derived from auditory evoked potential (AEP) and represents as a single numerical variable of the depth of anaesthesia [5]. AAI is highly sensitive for distinguishing the transition from unconsciousness to consciousness. This study aimed at using AEP monitor/AAI scale to titrate depth of anaesthesia in neurosurgical population for reducing the utilization of isoflurane and concurrently demonstrating the cost sparing effect of AEP without jeopardizing the anaesthetic technique, the surgery or the patient outcome.

\section{Methods}

The study was conducted at a Tertiary care hospital which serves as a referral institution for a large number of hospitals in the region. The duration of the study was from 15 May 2007 to 14 May 2008. The study design was an observational analytical prospective cohort. The patient population was consecutively admitted neurosurgical patients aged more than 15 years requiring GA including intubation and neuromuscular blocking agents (NMBA).After obtaining written informed consent the enrolled patients were allocated to one of two groups: Group 1 or Group 2 and assessed for intra-operative awareness, Post-operative recovery and Utilisation of Isofluorane. (Figure 1) Exclusion criteria were patients with history of deafness, mental subnormality, alcohol or drug dependence, previous history of head injury, any other neurological disorder, ASA class III patients, duration of surgery $<90 \mathrm{~min}$ to $>150 \mathrm{~min}$ or duration of maintenance period of anaesthesia $<45 \mathrm{~min}$ or $>90 \mathrm{~min}$. The study had been 


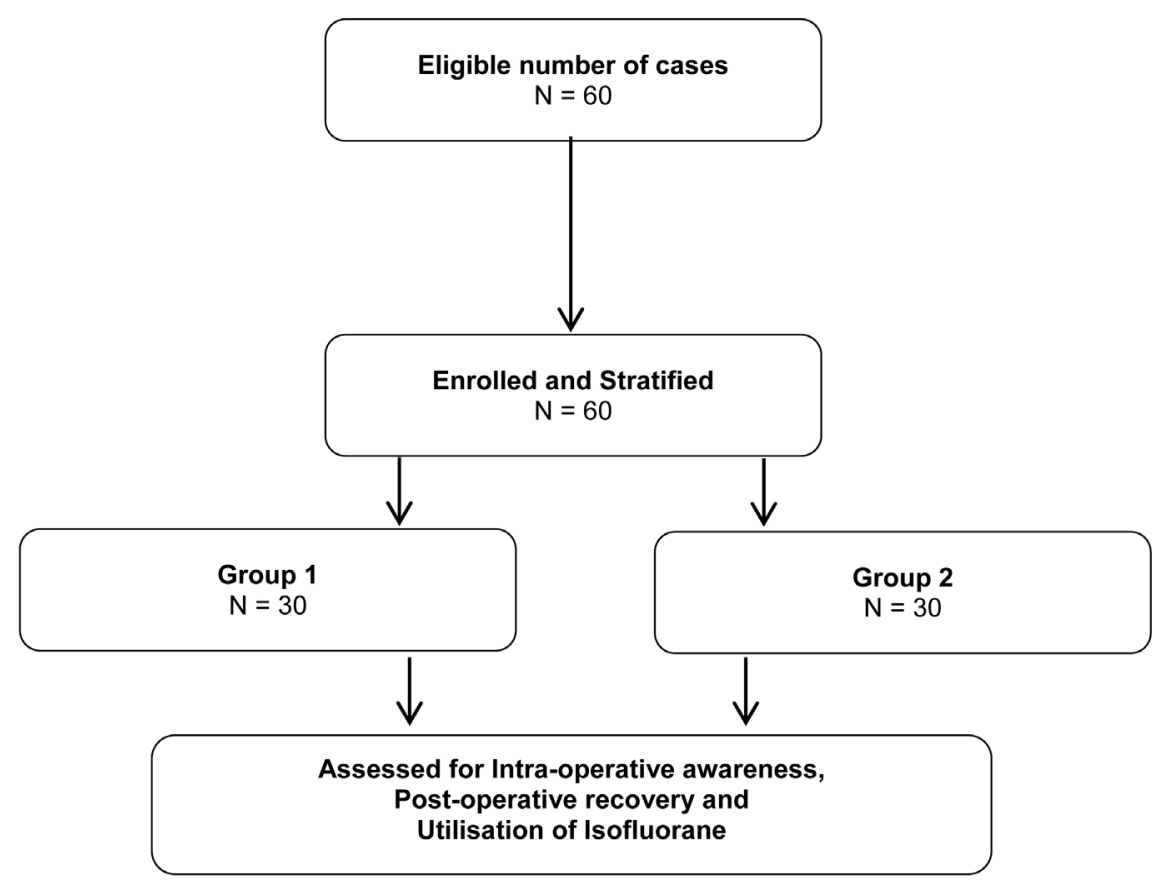

Figure 1. Flow of participants.

approved by the institutional ethics committee. All enrolled patients underwent a detailed history and physical examination before being enrolled in the study. Patients in Group 1 were monitored for conventional parameters like Heart rate (HR), Pulse oximetry $\left(\mathrm{SpO}_{2}\right)$, Non-invasive blood pressure (NIBP), End-tidal carbon-di-oxide $\left(\mathrm{EtCO}_{2}\right)$, Temperature (Temp) and Electrocardiogramme (ECG). The fluid intake, urine output, presence of lacrimation and sweating were monitored. In addition the administered dose of Isofluorane was recorded throughout the anaesthesia which maintained the patient with stable haemodynamic status and lack of awareness. Patients in Group 2 were monitored additionally for AEP using the A-line monitor (version 1.4) (Danmeter A/S, Odense, Denmark). The post stimulus AEP latencies and amplitudes were plotted as realtime continuous waveforms by the AEP monitor. Based on the results of the AEP along with the clinical parameters, the quality and the depth of anaesthesia was adjusted by altering the MAC of Isoflurane by adjusting the dial setting of the vaporiser so as to meet the targeted parameters. The AEP monitor reflects the changes in the patient's level of consciousness by measuring the brains reaction to acoustic stimuli. The results obtained are in the form of a numerical value based on a mathematical model and is represented on a scale of $0-100$, which is referred to as the ARX index or AAI. AAI values of 50 or more indicative "awake state", a value of 30 represents "light anaesthesia", a value in the range of 15 - 25 indicates "surgical anaesthesia" while "deep anaesthesia" is indicated by AAI values $<15$. Three silver-chloride electrodes were positioned at the midforehead (+), left forehead (reference), and left mastoid (-) after adequate skin preparation with alcohol and gentle debridement with gauze until the electrodes' impedance was $<1000 \mathrm{Ohms}$. The MLAEP were elicited with a binaural click 
stimulus of 2 millisecond (ms) duration and repetition rate of $9 \mathrm{~Hz}$ with the MLAEP analysis window of $20-80 \mathrm{~ms}$. The composite AAI which is a dimensionless index ranging from 100 (patient fully awake) to 0 (very deep hypnosis) is then calculated from the MLAEP or the EEG, depending on the signal-tonoise (SNR) ratio. In case of an SNR ratio $<1.45$, the AAI is not calculated from the AEP but is based on an analysis of the B-ratio and the extent of burst suppression of the spontaneous EEG. AEP and other data was stored automatically on the hard disk of the microcomputer every $3 \mathrm{sec}$, enabling future retrieval for further analysis. The duration of the surgery was approximately $90-150 \mathrm{~min}$. Duration of $60 \mathrm{~min}$ for the maintenance period of anaesthesia was taken as the time period under study for cost analysis of the anaesthetic agent. The average maintenance period of anaesthesia was around $90 \mathrm{~min}$. Duration of anaesthesia maintenance $>90 \mathrm{~min}$ or $45 \mathrm{~min}$ were not included in the final analysis. During induction and intubation of patient, higher fresh gas flow rates were maintained for initial flush-in of gases. During maintenance phase of anaesthesia, fresh gas flow into the anaesthetic circuit was 3 litres per minute (LPM) for Isofluorane by keeping a low flow in a closed system. All cases were studied using Anaesthesia Delivery Unit of DatexOhmeda. Induction was done using Thiopentone in the conventional dose of $5 \mathrm{mg} / \mathrm{Kg}$ or till the loss of the eye lash reflex and endotracheal intubation was facilitated using Suxamethonium $(2 \mathrm{mg} / \mathrm{kg}$; $\max 100 \mathrm{mg}$ ) and maintenance of relaxation with Vecuronium $(0.1 \mathrm{mg} / \mathrm{kg})$. Analgesia in all the cases was provided with Morphine $(0.1 \mathrm{mg} / \mathrm{Kg})$ with subsequent doses as per the requirement and duration of the surgery. The inspired concentration of Isoflurane was adjusted to maintain the measured end- tidal concentration at a constant, predetermined value. After maintaining the end-tidal Isoflurane concentration for $3 \mathrm{~min}$, depth of sedation was assessed. The inspired Isoflurane concentration was then increased for tracheal intubation Vecuronium (0.02 $\mathrm{mg} / \mathrm{kg}$ ) was administered for precurarisation, and then paralysis was induced with $1.5 \mathrm{mg} / \mathrm{kg}$ Succinylcholine, followed by tracheal intubation. Following intubation, the inspired concentration of Isoflurane was readjusted back to maintain the end-tidal concentration as described. The concentration of Isoflurane was measured continuously using an infrared anaesthetic gas analyser (Ohmeda 5250 RGM, Louisville, KY) which was calibrated before anaesthesia was administered for each patient using a standard gas mixture. The $\mathrm{EtCO}_{2}$ was kept between 35 to $45 \mathrm{mmHg}$ during the surgery. All possible attempts were made to provide an equipotent balanced anaesthesia with constant and similar gas flows of around $3 \mathrm{LPM}$. All intra-operative variables like $\mathrm{HR}, \mathrm{SpO}_{2}, \mathrm{EtCO}_{2}$ and awareness were recorded during the maintenance phase of anaesthesia. All patients were transferred to a post-anaesthesia care unit (PACU) after the surgery. The PACU nurses were blinded to the anaesthetic technique. When nausea or emesis occurred, intravenous (IV) Ondansetron was given. Pain was treated either by using IV Morphine or Diclofenac sodium. Post-operative variables such as eye opening, head lift, motor activity, and post-operative recovery time were recorded. The study aimed at evaluating intra-operative AEP as an indicator of 
anaesthetic depth and for monitoring of intraoperative awareness, to describe the post-stimulus MLAEP latencies and amplitudes as waveforms and as AAI scale and to identify an anaesthetic sparing ability while monitoring patients on the AEP monitor in Group 2. The post-operative variables between the 2 groups were compared for recovery time using the Aldrete scale. A correlation between the Vaporiser concentration and consumption of Isofluorane during the maintenance period would reflect the anaesthetic sparing ability of the dose titration based on AEP in patients in Group 2 as compared to patients in Group 1. These economic calculations did not taken into account the capital outlay or the maintenance and running costs of the equipment.

\section{Sample Size and Statistical Analysis}

In order to identify a clinically relevant and a statistically significant difference in the intra-operative awareness level and maintenance of depth of anaesthesia at a pre-determined value of end-tidal concentration of Isofluorane, a minimum number of 30 patients were required in each group. A total of 60 patients were enrolled in the study and equal numbers were randomly allotted to Group 1 or Group 2. To detect the ability of AEP monitor (AAI scale) to titrate the depth of anaesthesia and reduce the intra-operative awareness, the haemodynamic response of the 2 groups were pooled group and compared to each other (Group 1: control; Group 2: with AEP monitor). Post-operative variables (eye opening, head lift, motor activity, and post-operative recovery time) were recorded and the pooled data of Group 1 was compared with Group 2. For all numerical continuous variables the mean was recorded and variance was described as Standard Deviation (SD). For all dichotomous categorical variables median and inter-quartile ranges (IQR) were calculated. Haemodynamic responses as a measure of intra-operative awareness/ depth of anaesthesia were compared between the 2 groups using Student's t-test, Chi-square test or the Fishers exact test as appropriate. Using two sample t-test cost analysis of expense of isoflurane was done. The pooled data of the concentration of Isofluorane given was used in Dions formula to derive per patient and per minute cost of Isoflurane [6]. Data was analysed using statistical software SPSS 17.0. P-value $<0.05$ was considered statistically significant.

\section{Results}

Sixty neurosurgical patients with anticipated duration of surgery between 90 150 min were enrolled for the study. Thirty patients were allocated to Group 1 and a similar number were allocated to Group 2. Males outnumbered the females in both groups [Group 1: males $n=25$ (84\%), females $n=5$ (16\%)] [Group 2: males $n=27(89 \%)$, females $n=3(11 \%)]$. The age of the patients in Group 1 ranged from 18 yrs to 62 yrs while in Group 2 it ranged from ranged from 23 yrs to 65 yrs. All other operative and anaesthesia parameters are sum-

marized (Table 1). There was no significant difference in the intraoperative haemodynamic responses measured between the two study groups (Table 2). There was no significant difference in the identification of intraoperative aware- 
Table 1. Baseline and operative characteristics of the study groups.

\begin{tabular}{cccc}
\hline Characteristics & $\begin{array}{c}\text { Group 1 } \\
(\mathrm{N}=30)\end{array}$ & $\begin{array}{c}\text { Group 2 } \\
(\mathrm{N}=30)\end{array}$ & $\begin{array}{c}\text { Mean } \\
\text { difference }\end{array}$ \\
\hline Females, N (\%) & $5(16)$ & $3(11)$ & 0 \\
Age (yr), mean \pm SD & $49 \pm 3$ & $53 \pm 5$ & 4 \\
Body weight (kg), mean \pm SD & $59 \pm 6$ & $57 \pm 7$ & 2 \\
Surgery time (min), mean \pm SD & $108.06 \pm 9.081$ & $104.6 \pm 9.185$ & 4.4 \\
Maintenance time (min), mean \pm SD & $82.83 \pm 7.4$ & $82 \pm 7.14$ & 0.83 \\
\hline
\end{tabular}

$\mathrm{SD}=$ Standard deviation

Table 2. Intra-operative haemodynamic responses measured between the two groups.

\begin{tabular}{cccc}
\hline Haemodynamic response & $\begin{array}{c}\text { Group 1 } \\
(\mathbf{N}=30)\end{array}$ & $\begin{array}{c}\text { Group 2 } \\
(\mathrm{N}=30)\end{array}$ & $\boldsymbol{P}$-value \\
\hline Heart rate (per min), mean $\pm \mathrm{SD}$ & $78 \pm 6$ & $73 \pm 6$ & $>0.05$ \\
$\mathrm{SBP}(\mathrm{mmHg})$, mean $\pm \mathrm{SD}$ & $117 \pm 6$ & $118 \pm 4$ & $>0.05$ \\
$\mathrm{DBP}(\mathrm{mmHg})$, mean $\pm \mathrm{SD}$ & $79 \pm 5$ & $78 \pm 3$ & $>0.05$ \\
$\mathrm{SpO}_{2}(\%)$, mean $\pm \mathrm{SD}$ & $99 \pm 3$ & $99 \pm 2$ & $>0.05$ \\
$\mathrm{EtCO}_{2},(\mathrm{mmHg})$, mean $\pm \mathrm{SD}$ & $32 \pm 1$ & $33 \pm 1$ & $>0.05$ \\
\hline
\end{tabular}

$\mathrm{EtCO}_{2}=$ End-tidal carbon-di-oxide, $\mathrm{DBP}=$ Diastolic blood pressure, $\mathrm{SpO}_{2}=$ Oxygen saturation, $\mathrm{SBP}=$ Systolic blood pressure, $\mathrm{SD}=$ Standard deviation.

ness using the conventional parameters between the two groups (Table 3(a)). There was no significant difference in the rate of fresh flow of gases between the 2 groups. However there was a significantly lesser consumption of Isofluorane in Group 2 as compared to Group 1 (Table 3(b)). There was also a significant difference in the post-operative recovery variables, with a significantly faster time to recovery for patients in Group 2 (Table 4).

\section{Discussion}

Even though the knowledge about the mechanisms of general anaesthesia has increased considerably since its introduction in clinical practice, it is unknown how anaesthetics prevent consciousness [6]. This study was undertaken to study the usefulness of AEP monitoring in a neurosurgical population, with focus on intraoperative awareness by titrating the depth of anaesthesia and using it to reduce the patient Isofluorane consumption. In several studies AAI have been shown to reduce the amount of anaesthetics given and expedite immediate postoperative recovery as compared to standard practice [7] [8]. A number of studies have also demonstrated that the sensitivity and specificity for AAI is not perfect [9] [10] and fears have been raised that the incidence of awareness might even increase if the anaesthetist aims at an upper threshold value [11] [12].

In our study, in group 1, the effect of conventional monitoring on the incidence of awareness was investigated in clinical routine. In group 2, AEP hypnosis monitor using AAI was investigated and evaluated during general anaesthe- 
Table 3. (a) Comparison of Intra-operative awareness between the study groups; (b) Comparison of Isofluoraneutilisation and cost between the study groups.

(a)

\begin{tabular}{cccc}
\hline Intra-operative awareness & Group 1 $(\mathrm{N}=\mathbf{3 0})$ & Group 2 $(\mathrm{N}=\mathbf{3 0})$ & $P$-value \\
\hline Present, n (\%) & $3(10)$ & $1(3)$ & 0.12 \\
Absent, n (\%) & $27(90)$ & $29(97)$ & 0.68 \\
\hline
\end{tabular}

(b)

\begin{tabular}{ccccc}
\hline Concentration & $\begin{array}{c}\text { Group 1 } \\
\mathbf{N = 3 0}\end{array}$ & $\begin{array}{c}\text { Group 2 } \\
\mathbf{N}=\mathbf{3 0}\end{array}$ & $\begin{array}{c}\text { Mean } \\
\text { difference }\end{array}$ & $P$-value \\
\hline Isofluorane (vapouriser) & $1.34 \pm 0.15$ & $0.82 \pm 0.12$ & 0.52 & $<0.05$ \\
FGF (LPM) & 3 & 3 & 0 & - \\
Utilisation cost & & & t-test & $P$-value \\
Isofluorane cost per patient (INR), mean \pm SD & $156 \pm 3.9$ & $113 \pm 3.0$ & 58 & $<0.05$ \\
Isofluorane cost per patient (INR), mean \pm SD & $2.7 \pm 0.35$ & $1.9 \pm 0.3$ & 54 & $<0.05$ \\
\hline
\end{tabular}

FGF $=$ Fresh flow of gas.

Table 4. Post-operative recovery using the Aldrete scale in the study population.

\begin{tabular}{ccccc}
\hline Parameter & $\begin{array}{c}\text { Group 1 } \\
\text { N = 30 }\end{array}$ & $\begin{array}{c}\text { Group 2 } \\
\text { N = 30 }\end{array}$ & $\begin{array}{c}\text { Mean } \\
\text { difference }\end{array}$ & $P$-value \\
\hline Delayed Eye opening, N (\%) & $6(20)$ & $1(3)$ & - & $<0.05$ \\
Delayed Motor activity, N (\%) & $5(16)$ & $1(3)$ & - & $<0.05$ \\
Delayed Head lift, N (\%) & $4(13)$ & 0 & - & $<0.05$ \\
Delayed Post-op recovery time, N (\%) & $6(20)$ & $1(3)$ & - & $<0.05$ \\
Aldrete score, mean \pm SD & $7.1 \pm 1.3$ & $8.3 \pm 1.1$ & 1.2 & $<0.05$ \\
\hline
\end{tabular}

sia. According to Kalkman and Drummond [13], MLAEP are almost completely suppressed soon after loss of consciousness. Many studies have suggested that derivatives of MLAEP like AEP are better discriminators than BIS in tracing the transition from awake to the anaesthetized state [14] [15] titrating depth of anaesthesia and detecting intra-operative awareness.

The absence of haemodynamic response in patients does not necessarily include absence of intra-operative awareness. Haemodynamic variables are known to be poor indicators of the hypnotic state [16] and our study also shows similar results. The relation of haemodynamic variables to arousal was also not found to be consistent similar to findings by other researchers [17] [18] [19] [20]. Our study demonstrated that AEP reflected as the AAI scale is a valid tool for ascertaining the depth of anaesthesia and the AEP index is easy to calculate and all the calculations are real time. The present study was designed to evaluate the cost sparing effect of AEP monitor showing that its use resulted in a significantly lesser utilisation of Isofluorane as compared to intra-operative depth ascertainment by conventional technique. The cost analysis study carried out showed that the AEP monitor was not only useful in reducing the per patient cost of the anaesthetic agent used, isoflurane (Figure 2(a)), but also the per minute cost (Figure $2(\mathrm{~b})$ ). AEP use resulted in a significantly lesser utilisation of 


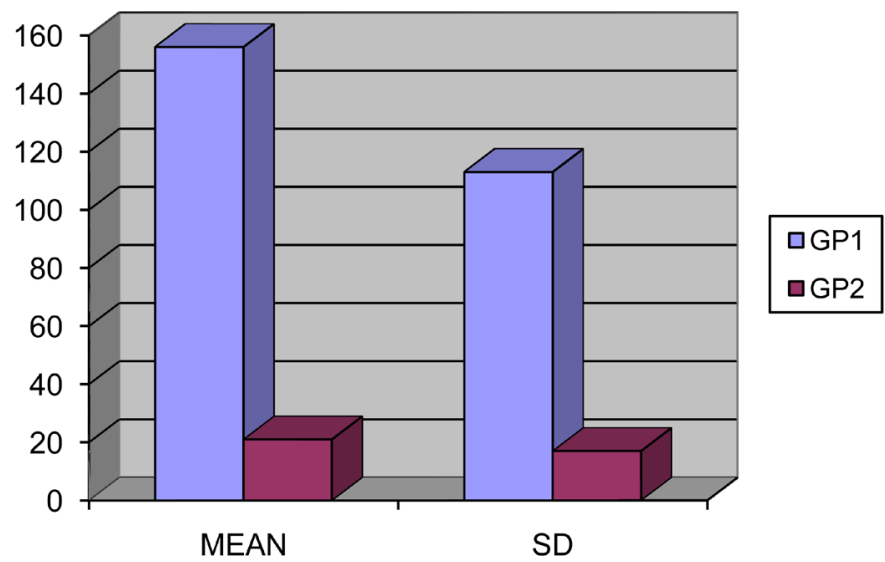

\begin{tabular}{cccccc}
\hline \multicolumn{2}{c}{ Cost of isoflurane/patient } & & GP-1 & \multicolumn{2}{c}{ GP2 } \\
\hline & $\mathrm{N}=30$ & & 156 & & 113 \\
\hline $\mathrm{Gp}$ & Obs & Mean & SD & T-test DF & p-value \\
\hline 1 & 30 & 156 & 3.9 & & \\
2 & 30 & 113 & 3.07 & & $<0.05$ \\
total & 60 & 135 & 3.8 & 58 & \\
Difference & & 43 & 5 & & \\
\hline
\end{tabular}

(a)

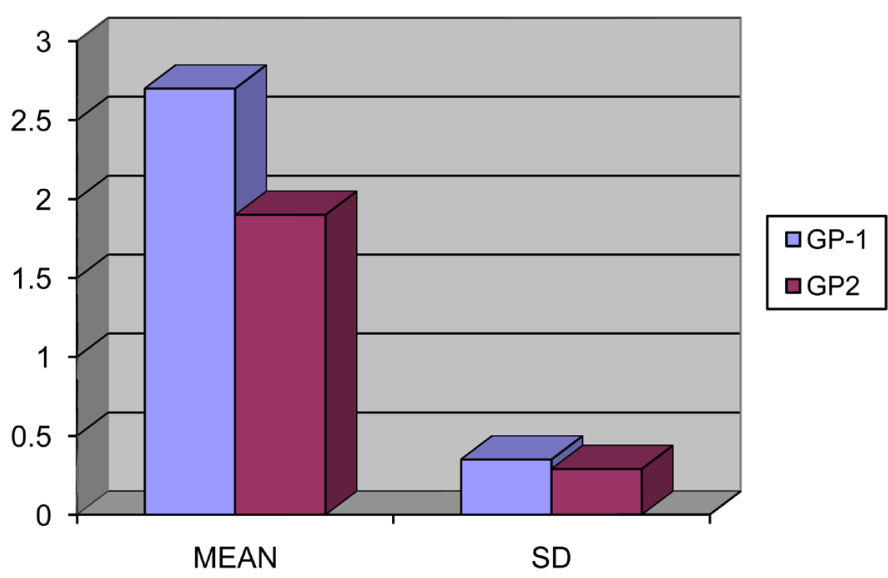

\begin{tabular}{cccccc}
\hline & Cost of isoflurane/min & & GP1 & GP2 \\
\hline & & & 2.7 & 1.9 \\
\hline Gp & Obs & Mean & SD & T-test DF & p-value \\
\hline 1 & 30 & 2.7 & 0.35 & & \\
2 & 30 & 1.9 & 0.3 & & $<0.05$ \\
total & 60 & 2.24 & 0.47 & 58 & \\
Difference & & .7 & 0.54 & & \\
\hline
\end{tabular}

(b)

Figure 2. (a) Cost per patient; (b) Cost per minute. 
Isofluorane as compared to intra-operative depth ascertainment by conventional technique. The study also showed a significantly faster recovery time in patients given anaesthesia with AEP monitoring compared to control group. Using AEP/ AAI not only was there a better titration of anaesthesia but also significant reduction in the post-operative stay in the PACU. A significant difference $(P<$ 0.05 ) in all the postoperative parameters was recorded in the PACU between the two groups with a significantly shorter post-operative recovery time in the patients of the group 2.

The limitation of this study was that using evoked potentials to monitor depth of anaesthesia entails technical, clinical and practical complexities and many confounding factors can alter these potentials such as stimulus characteristics (intensity, duration, inter-stimulus interval), electrode placement technique, age and gender of the subject and choice of anaesthetic drugs. Also since the overall incidence of awareness in the general population is very low, a larger sample size may be able to identify a statistically significant difference.

Our study showed that AAI reduced the amount of anaesthetics given and expedited the postoperative recovery as compared to standard practice. AEP monitoring during general anaesthesia including an NMBA reduced the incidence of awareness as compared to standard monitoring and has been used clinically to titrate the depth of anaesthesia and to reduce the risk of intraoperative awareness leading to less anaesthetic drug use and faster and improved recovery from PACU.

\section{Conclusion}

In conclusion, this study demonstrates that hypnosis monitoring can reduce the incidence of awareness with better titration of depth of anaesthesia, decrease the incidence of post-operative nausea and vomiting, and ensure faster recovery from post anaesthesia care unit without compromising on the anaesthetic technique, the surgery or the patient outcome.

\section{Acknowledgements}

KT conceived and designed the study. KT and TVSP acquired the data, managed the cases and analysed the data. KT drafted the article. All of the authors were involved in patient management. All authors approve the final manuscript.

\section{Funding}

The authors declare no source of financial support.

\section{References}

[1] Barker, S.J. (2003) Too Much Technology? Anesthesia \& Analgesia, 97, 938-939.

[2] Liu, W.H.D., Thorp, T.A.S., Graham, G.S.G. and Aitkenhead, A.R. (1999) Incidence of Awareness with Recall during General Anaesthesia. Anaesthesia, 46, 435-437. https://doi.org/10.1111/j.1365-2044.1991.tb11677.x

[3] Hug, C.C. (1990) Does Opioid “Anaesthesia” Exist? Anesthesiology, 73, 1-4. 
https://doi.org/10.1097/00000542-199007000-00001

[4] Schraag, S., Bothner, U., Gajraj, R., Renny, G.N.C. and Geogieff, M. (1999) The Performance of Electroencephalogram Bispectral Index and Auditory Evoked Potential Index to Predict Loss of Consciousness during Propofol Infusion. Anesthesia \& Analgesia, 89, 1311-1315. https://doi.org/10.1213/00000539-199911000-00045

[5] Mantzaridis, H. and Kenny, G.N. (1997) Auditory Evoked Potential Index: A Quantitative Measure of Changes in Auditory Evoked Potentials during General Anaesthesia. Anaesthesia, 52, 1030-1036.

https://doi.org/10.1111/j.1365-2044.1997.185-az0327.x

[6] Biro, P. (2014) Calculation of Volatile Anaesthetics Consumption from Agent Concentration and Fresh Gas Flow. Acta Anaesthesiologica Scandinavica, 58, 968-972.

https://doi.org/10.1111/aas.12374

[7] Bruhn, J., Kreuer, S., Bischoff, P., Kessler, P., Schmidt, G.N., et al. (2005) Bispectral Index and A-Line AAI Index as Guidance for Desflurane-Remifentanil Anaesthesia Compared with a Standard Practice Group: A Multicentre Study. British Journal of Anaesthesia, 94, 63-69. https://doi.org/10.1093/bja/aei013

[8] Gan, T.J., Glass, P.S. and Windsor, A. (1997) Bispectral Index Monitoring Allows Faster Mergence and Improved Recovery from Propofol, Alfentanil, and Nitrous Oxide Anaesthesia. Anesthesiology, 87, 808-815. https://doi.org/10.1097/00000542-199710000-00014

[9] Liu, S.S. (2004) Effects of Bispectral Index Monitoring on Ambulatory Anaesthesia: A Meta-Analysis of Randomized Controlled Trials and a Cost Analysis. Anesthesiology, 101, 311-315.

[10] Gajraj, R.J., Doi, M., Mantzaridis, H. and Kenny, G.N. (1998) Analysis of the EEG Bispectrum, Auditory Evoked Potentials and the EEG Power Spectrum during Repeated Transitions from Consciousness to Unconsciousness. British Journal of Anaesthesia, 80, 46-52. https://doi.org/10.1093/bja/80.1.46

[11] Gajraj, R.J., Doi, M., Mantzaridis, H. and Kenny, G.N. (1999) Comparison of Bispectral EEG Analysis and Auditory Evoked Potentials for Monitoring Depth of Anaesthesia during Propofol Anaesthesia. British Journal of Anaesthesia, 82, 672678. https://doi.org/10.1093/bja/82.5.672

[12] Sneyd, J.R. (2003) Editorial: How Low Can We Go? British Journal of Anaesthesia, 91, 771-772. https://doi.org/10.1093/bja/aeg268

[13] Kalkman, C.J. and Drummond, J.C. (2002) Monitors of Depth of Anaesthesia, Quo Vadis? Anesthesiology, 96, 784-787. https://doi.org/10.1097/00000542-200204000-00003

[14] Todd, M.M. (1998) EEGs, EEG Processing and the Bispectral Index. Anesthesiology, 89, 815-817. https://doi.org/10.1097/00000542-199810000-00002

[15] Kreuer, S., Bruhn, J., Larsen, R., Hoepstein, M. and Wilhelm, W. (2003) Comparison of Alaris AEP Index and Bispectral Index during Propofol-Remifentanil Anaesthesia. British Journal of Anaesthesia, 91, 336-340.

https://doi.org/10.1093/bja/aeg189

[16] Kaul, H.L. and Bharti, N. (2002) Monitoring Depth of Anaesthesia. Indian Journal of Anaesthesia, 46, 323-332.

[17] Zbinden, A.M., Maqqiorini, M., Petersen-Felix, S., Lauber, R., Thomson, D.A. and Minder, C.E. (1994) Anaesthetic Depth Defined Using Multiple Noxious Stimuli during Isoflurane/Oxygen Anaesthesia. Anesthesiology, 80, 261-267. https://doi.org/10.1097/00000542-199402000-00005

[18] Mi, W.D., Sakai, T., Takahashi, S. and Matsuki, A. (1998) Haemodynamic and Elec- 
troencephalograph Responses to Intubation during Induction with Propofol or Propofol/Fentanyl. Canadian Journal of Anesthesia, 45, 19-22.

https://doi.org/10.1007/BF03011986

[19] Struys, M.M., Jensen, E.W., Smith, W., Smith, N.T., Rampil, I., et al. (2002) Performance of the ARX-Derived Auditory Evoked Potential Index as an Indicator of Anesthetic Depth. Anesthesiology, 96, 803-816.

https://doi.org/10.1097/00000542-200204000-00006

[20] Weber, F., Seidl, M. and Bein, T. (2005) Impact of the AEP-Monitor/2-Derived Composite Auditory-Evoked Potential Index on Propofol Consumption and Emergence Times during Total Intravenous Anaesthesia with Propofol and Remifentanil in Children. Acta Anaesthesiologica Scandinavica, 49, 277-283.

https://doi.org/10.1111/j.1399-6576.2005.00626.x

Submit or recommend next manuscript to SCIRP and we will provide best service for you:

Accepting pre-submission inquiries through Email, Facebook, LinkedIn, Twitter, etc. A wide selection of journals (inclusive of 9 subjects, more than 200 journals) Providing 24-hour high-quality service User-friendly online submission system Fair and swift peer-review system Efficient typesetting and proofreading procedure Display of the result of downloads and visits, as well as the number of cited articles Maximum dissemination of your research work

Submit your manuscript at: http://papersubmission.scirp.org/

Or contact ojanes@scirp.org 